\title{
EVIDENCE OF DISCRIMINATION BY PREFERENCE IN BRAZIL
}

\author{
Guilherme Hirata ${ }^{*}$
}

\begin{abstract}
Resumo
Este artigo testa implicações do modelo de discriminação por preferência de Becker (1957). Utilizando dados brasileiros, rejeita-se a hipótese de que o hiato salarial entre brancos e negros seja determinado pelo nível médio de discriminação. Os resultados mostram que o hiato está relacionado ao grau de discriminação do empregador marginal, isto é, aquele que mais discrimina entre os que contratam negros. Além disso, os resultados estão de acordo com a previsão de que o hiato salarial é maior em lugares com maior proporção de negros no mercado de trabalho, ou seja, onde há mais interação social entre raças.
\end{abstract}

Palavras-chave: Discriminação racial; Hiato salarial; Modelo de discriminação do empregador; Brasil

\begin{abstract}
This paper tests Becker's model of preference discrimination. Using Brazilian data, we reject the hypothesis that the black-white conditional wage gap is determined by the average degree of employers' prejudice. Instead, we show that the racial wage gap is related to the degree of prejudice of the marginal employer, i.e., the employer who most discriminates among those who hire blacks. We also found that the wage gap is positively correlated with the proportion of blacks in the labor market, which means that blacks are more discriminated where there is more social interaction among races.
\end{abstract}

Palavras-chave: Racial discrimination, Racial wage gap, Employer's discrimination model; Brazil

JEL classification: J31, J71, J78

DOI:http://dx.doi .org/10.11606/1413-8050/ea 153368

\footnotetext{
*IDados. E-mail:guilherme@idados.org.br
} 


\section{Introduction}

A national representative survey conducted by the Brazilian National Statistics Office (IBGE) in 2008 shows that $71 \%$ of respondents believe that race influences labor relationships, while only $40 \%$ think the same for marriage ${ }^{1}$. Although specific to the Brazilian context, this finding reveals that personal attributes unrelated to productivity may be a determinant of the persistence of the racial wage gap at the beginning of the twenty-first century. This paper tests this hypothesis by testing two implications of Becker's (1957) employer's discrimination model using Brazilian data. According to the model, given the distribution of preferences for discrimination, the higher the proportion of the minority to the majority, the larger the wage gap will be. The second prediction states that the average degree of prejudice among employers is not a key determinant of the racial wage gap; what matters is the degree of prejudice of the "marginal employer", i.e, the employer who most discriminates against blacks among those who hire blacks.

The racial wage gap conditional on observable characteristics has been attributed to discrimination for decades. The main reason is that the term related to the fixed effect of race in Mincerian equations remains relevant in regression estimates even with the availability of more accurate information and the improvement of econometric methods to deal with sample selection and other related issues. Because of that, there is still a debate in the literature about the extent to which that fixed effect term reflects discrimination in the labor market.

In recent years, the literature focused on the study of the characteristics typically excluded from wage equations that may lead to differences in the labor market (Fryer 2011, Bertrand 2011). This approach aims to reveal the portion of the wage gap that is due to unobservable productive characteristics and, therefore, cannot be attributed to discrimination. Quality of education, effective market experience, risk aversion and investments in early childhood cognitive and non-cognitive skills are some of the main factors considered responsible for differences in pay and other outcomes as the unemployment rate, for example between blacks and whites (Neal \& Johnson 1996, Card \& Krueger 1992, Carneiro et al. 2003).

On the other hand, direct evidence of market generating these differences instead of just reproducing them is relatively scarce. Consistent with statistical discrimination model (Phelps 1972), List (2004) finds evidence of discrimination against minorities (blacks and women) in an experiment in the sports cards market, in which the minority receives lower offers when trying to sell their cards, and larger when they want to buy. Bertrand \& Mullainathan (2004) document that, after sending virtually identical fake CVs to media companies, those whose names were more associated with white people received more call backs for interviews than $\mathrm{CVs}$ with names associated with blacks.

It could be argued that evidences of statistical discrimination just corroborate the view that the market only reproduces inequalities because they are based on employers' beliefs, not preferences. Evidences of discrimination by preference are presented by Goldin \& Rouse (2000) and Anwar et al. (2012).

\footnotetext{
${ }^{1}$ Pesquisa Características Étnico-Raciais da População (Racial-Ethnic Characteristics of the Population Survey), 2008.
} 
Goldin and Rouse show that the women's probability of success at each stage of selection of musicians for the five major orchestras in the USA increased substantially after the introduction of a process in which referees had no visual contact with candidates. Anwar et al. (2012), analyzing criminal trials in the USA, report that juries composed of whites only condemn blacks more often than whites, and that this difference is eliminated when there is at least one black person among jury members. However, although such studies report results in line with a model of discrimination by preference, they have no direct relationship to the labor market in general, and to the wage gap in particular.

Becker's employer discrimination model explains the mechanism through which the employer's prejudice against minorities may cause wage differentials between majority and minority groups in the labor market. Despite the impact on the economic theory this model caused at the time it was published, empirical studies walked toward the analysis of non-observable characteristics, as evidenced above. Only a few years ago there was the first attempt to empirically test the specific predictions of Becker's model, by Charles \& Guryan (2008). The authors found evidence that racial discrimination by preference is responsible for about a quarter of the observed wage gap between white and black men in USA. Hjort (2014) analyzes a production of packaging flowers in Kenya, where there are several teams with three workers each, in which a supplier (upstream worker) distributes material for two processors (downstream workers). The author shows that when the supplier's ethnicity is different from at least one of the processors', the former distributes less flowers to the processor of distinct ethnicity, leading to a reduction in the team's output, which causes a reduction in payment for all team members, including the supplier.

In order to test the aforementioned predictions of the model, we implement a methodology similar to Charles \& Guryan (2008). From the 2010 Census microdata, we first estimate the racial wage gap for each Brazilian microregion through a Mincerian equation at the individual level. A microregion, our definition of local market, is defined by IBGE as a set of geographically nearby integrated municipalities. In a second stage, at the microregional level, the estimated wage differentials are regressed on the proportion of blacks and prejudice measures. Because Brazil is a developing country with a highly regulated market, the effects are potentially different from those discussed by Charles \& Guryan (2008) for USA. More importantly, Brazil is a highly mixed society and offers a distinct perspective to study and better understand the consequences of racial discrimination and the meaning of the expression "Racial Democracy", that was used to describe Brazilian society during several decades in the twentieth century (Jaccoud 2008).

The measures of preference for discrimination are obtained from a prejudice distribution for each microregion. The Ações Discriminatórias no Âmbito Escolar survey (Discriminatory Actions in the School Survey, 2008) provides the information necessary for the construction of an individual prejudice index which, in turn, is used to recover the distribution of preference for discrimination. This survey investigates the incidence of prejudice and discriminatory behavior against blacks (and women and poor among others) in Brazilian public schools. With that distribution at hand, we are able to get any of its moments. It is assumed that the distribution recovered from this survey is representative of the propensity of employers to discriminate against blacks 
in each microregion. In general, the results confirm the theoretical predictions tested. In particular, using our preferred specification - an increase of 10 percentage points in the proportion of blacks in the labor market - results in a $14 \%$ increase in the black-white conditional wage gap. Therefore, there is more discrimination against blacks in localities where there is higher interaction between blacks and whites, a result that challenges the label "Racial Democracy" attached to Brazilian society, at least regarding economic relationships. Our findings also show that, as predicted by the model, the average discrimination does not have a role in the determination of the racial wage gap. On the other hand, an increase of one standard deviation in the marginal employer discrimination index increases the conditional wage gap by $27 \%$.

We also show that unobserved productivity characteristics are not driving our results. Assuming that access to public goods reduces the differences between blacks and whites in terms of quality of health and education, when we control for access to public goods, the impact of the marginal employer prejudice on the racial wage gap remains practically constant.

This paper is divided into five sections besides this introduction and the final remarks. The next section discusses some racial aspects in Brazil, highlighting the social context in which this paper is inserted. In Section 3, we briefly discuss the model of discrimination by preference. Section 4 provides information on data sources, performs a descriptive analysis, and discusses the methods used to recover the distribution of racial prejudice. The empirical strategy is the subject of Section 5, followed by the discussion of the results.

\section{Racial aspects in Brazil}

Brazil is a highly race-mixed society. Centuries ago, whites (Europeans), blacks (slaves) and natives gave rise to an "intermediate" race called pardos (in English, both mixed and brown could be used to identify them). A black-native descendant might be considered pardo, as well as a white-native descendant or a black-white one.

Nevertheless, despite being a racial category officially used by the government and other agencies for registry and survey purposes, pardo is a word that sounds a little bit unnatural and suffers some rejection by the population. It is not uncommon for people to use the word moreno (brunette) instead. The problem is that virtually everyone can be attached to or self-report as moreno. For example, a German descendant person could be considered moreno because their hair is black, but they would hardly be called pardo. On the other hand, a person who would be considered black in the USA because of their skin tone could also self-report as moreno.

The 1976 National Household Survey (PNAD), surveyed by IBGE, included a spontaneous-response question about the interviewee's color or race in addition to the induced one. The induced categories are white, black, yellow (Asian), brown and native. About $57 \%$ of spontaneous responses are four of the induced categories (white, black, yellow, brown). On the other hand, 38\% are concentrated in other three categories: moreno (brunette), moreno claro (light brunette) and clara (this last one could be translated as lighter brunette). When comparing induced responses to spontaneous ones, $66 \%$ of browns reported they were brunette. Not surprisingly, though, $14 \%$ of whites and $33 \%$ of blacks did the same. Therefore, most of brunettes do not want to be viewed 
as brown, a non negligible share of blacks prefer to be considered brown, and some whites do not want to be white ${ }^{2}$.

Although the same induced categorization was maintained for several waves in IBGE surveys, Schwartzman (1999) notes that older cohorts are more likely to self-report as white than younger cohorts. The decrease in the percentage of whites comes with a proportional increase in the percentage of browns and no change in the percentage of blacks. This indicates that the rejection of the white category by young people has more to do with identity than with miscegenation of the population, since in the latter case a decrease in the proportion of blacks would also be observed. Something similar occurred in the USA. Nix \& Qian (2015) report that 20\% of black men "passed" as whites during the 1880-1960 period, probably motivated by better social, political and economic opportunities. Antman \& Duncan (2015) present evidence from more recent years (1997-2011). They found that individuals who benefited from affirmative action policies in the USA are $30 \%$ less likely to identify with their minority groups after the policy is banned.

In this context of this paper, what matters is how the employer sees the workers. Would a white employer who self-reports as brunette consider a brown or black worker who does the same as her equal? This question has no easy answer, but is crucial in all racial studies related to discrimination by preference. In Brazil, for example, it is very important because the definition of minority becomes a little bit awkward when browns are considered part of the minority along with blacks. In 2013, according to PNAD, blacks represented $8 \%$ of the population, while browns represented $45 \%$; Asians and natives did not reach $1 \%$. Thus, the minority group would actually account for more than half of the population because brown people are a very large group $^{3}$. Because browns and whites are very different groups in terms of socioeconomic indicators (see Table A.1 in the appendix based on Census 2010), it is probably not accurate to consider browns as part of the majority group ${ }^{4}$. Thus, in Brazil, "minority" is a term less related to size and more related to socioeconomic characteristics. Accordingly, in the following sections of this paper, unless when explicitly indicated, the words "black" and "minority" refer to individuals who declare themselves as black, brown, native, brunette and other related terms ${ }^{5}$.

The expression Racial Democracy to describe the Brazilian society was created in a period where the existence of prejudice against blacks was rejected by some researchers (Osorio 2008). The upward mobility of browns was considered proof that there was no prejudice. According to this view, browns who ascended in society were distant from slavery (abolished in 1888) in terms of ancestors, and, due to the country's economic development, it was only a

\footnotetext{
${ }^{2}$ Unfortunately, to the best of our knowledge, the PNAD 1976 is the only survey that implemented this type of question. Of course, the scenario described might be different today.

${ }^{3}$ Kreisman \& Rangel (2015), using NLSY97 data that allow the survey interviewers to classify interviewees in a scaled measured skin tone, show that white interviewers tend to classify a black interviewee as darker black than black interviewers. Therefore, the proportion of blacks according to blacks in that country is probably different from the official statistic.

${ }^{4}$ Still, there may be some controversy. Osorio (2003) discusses the IBGE system for races and calls attention to the "social variation of color" issue, where social ascension can create a "whitening" effect.

${ }^{5}$ IBGE surveys used in this paper always adopt the five induced self-reported categories mentioned above. In the Discriminatory Actions in the School survey it is possible to choose brunette and mulatto in addition to those five.
} 
matter of time for the same to occur with "darker blacks", who had closer ancestors in slavery. In this sense, there would only be some sort of "class prejudice without racial prejudice". At the time the expression was created in the 1940s and 1950s, social classes and racial groups defined pretty much the same population groups, and there was almost no competition between whites and blacks for positions in the labor market.

More recently, this view was challenged. The success of Italian immigrants in comparison to the stagnation of blacks in the first half of the twentieth century is considered an example of how discrimination prevented the rising of blacks. In spite of being poor or not, Italians were able to integrate into society, either through acceptance in restricted-to-white clubs, or through marriage with Brazilians. Later, in addition, despite the economic growth in the 1970 s, the persistence of racial inequality suggested that discrimination was stronger than previously thought and that only the political action of blacks could lead to equalization (Osorio 2008).

This sociological view is related to the idea that the market only reproduces inequality. However, in the economic literature, it was precisely the focus on this concept that led the idea of prejudice preventing the rising of blacks to lose empirical support. Among other features not necessarily related to labor market, such as risk aversion, it would be a matter of investment in cognitive and non-cognitive abilities to reach a less unequal society. Nevertheless, the persistence of the racial wage gap in several countries in the twentyfirst century suggests that there is some component in the determination of the wage gap that is unrelated to skill formation. The next section presents the mechanism through which an employer's preference for discrimination can lead to a wage differential by race.

\section{Employer's discrimination model}

The theoretical framework to support empirical analysis is the model of employer's preference discrimination developed by Becker (1957). The model assumes the existence of two groups in a given population or local market. One group is the majority $(A)$, and the other is the minority $(V)$. The size of each group is fixed and they both supply labor inelastically. Only $A$ members can be employers and there is no entry in the product market. Let's assume that $A$ 's and $V$ 's are perfect substitutes in a production function that depends only on labor. Every employer has a discrimination coefficient, $d \geq 0$, indicating the monetary value of the disutility of interacting with minority members: higher values mean higher prejudice. Let's assume that $d$ is distributed according to $H(d)$.

The employer's problem is to choose the number of employees of each group $L_{A}$ and $L_{V}$ that maximizes his utility $U_{E}$. This utility is given by a combination of profit and disutility of interacting with the minority:

$$
U_{E}=F\left(L_{A}+L_{V}\right)-w_{A} L_{A}-w_{V} L_{V}-w_{V} d L_{V}
$$

where $w_{k}$ is the wage of $k=A, V$.

The first order conditions indicate that the number of workers of each group the employer hires in equilibrium, $L_{A}^{*}$ and $L_{V}^{*}$, should be such that

$$
F_{L_{A}^{*}} \leq w_{A} \text {, with equality if } L_{A}^{*}>0
$$




$$
F_{L_{V}^{*}} \leq w_{V}(1+d), \quad \text { with equality if } L_{V}^{*}>0 .
$$

That is, if the disutility of the employer is such that $w_{A}<w_{V}(1+d)$, the employer hires only $A$ 's. If, on the other hand, we have $w_{A}>w_{V}(1+d)$, only $V$ 's are hired. In this sense, market forces induce minority members to be hired by employers who do not discriminate or discriminate less, while the $A$ 's are hired by employers with greater discrimination coefficients. For some employer, the "marginal" employer, the following condition must hold:

$$
w_{A}^{*}=w_{V}^{*}\left(1+d^{*}\right)
$$

The marginal employer, therefore, is the one with the highest coefficient of discrimination that hires workers belonging to the minority group, i.e., he is the employer who is indifferent between hiring workers from minority or majority groups. Consequently, $d^{*}$, the discrimination coefficient of the marginal employer, corresponds to the wage gap between $A$ 's and $V$ 's in equilibrium. If $d^{*}=0$, there is no wage gap in the labor market even if there exist employers with $d>0$ in the product market. This implies, counter- intuitively, that the employers' average discrimination is not relevant to the determination of the wage gap. That is, even though $90 \%$ of employers would discriminate against $V^{\prime}$ 's, if the $V^{\prime}$ 's were all hired by employers who do not discriminate $\left(d^{*}=0\right)$, there is no wage differential between $A$ 's and $V$ 's in this economy. This is the main prediction of the Becker's model.

The sorting mechanism mentioned above is the mechanism through which who will be the marginal employer is defined. Thus, the identity of the marginal employer depends on the relative size of the $\mathrm{V}$ population and on the distribution of the discrimination coefficient among employers. Given the distribution of prejudice, the higher the proportion of minority to the majority, the higher the probability is that the minority will be absorbed by an employer with a higher coefficient of discrimination. To illustrate this, under decreasing returns to scale, suppose there are ten employers who hire one worker each, and there is only one black worker in the labor market. According to the model, this black worker will be hired by the least discriminating employer. Now, suppose that there are two black workers. All else being equal, the marginal employer is now the second who least discriminates against blacks. Therefore, if the coefficient of discrimination of this second employer is higher than the first one, the increase in the proportion of black workers leads to an increase in the wage gap.

The distribution of prejudice may also be relevant in determining the wage gap through the marginal employer. If there is an increase in prejudice against blacks, the coefficient of discrimination of the marginal employer will increase, causing the racial wage gap to be higher. Notice that the identity of the marginal employer does not change. On the other hand, if the proportion of blacks changes, the identity of the marginal employer will also change.

In summary, the model generates two main predictions to be tested empirically in this paper. The first one is that the higher the proportion of the minority in the labor market, the larger the wage gap between the majority and the minority tends to be. The second one is that the relevant factor in determining the wage differential is the degree of prejudice of the marginal employer, not the mean degree of prejudice among employers. 


\section{Data and Descriptive Analysis}

\subsection{Data sources}

This paper has two main data sources. The first one is the Ações Discriminatórias no Âmbito Escolar survey (Discriminatory Actions in the School, hereinafter called ADAE), conducted jointly by the National Institute of Educational Studies (INEP), a government agency under the Ministry of Education and Culture (MEC), and the Institute of Economic Research Foundation of the University of São Paulo (FIPE-USP). The main objective of the ADAE survey is to investigate the incidence of prejudice and discriminatory behavior by race, gender and socioeconomic condition, among others in Brazilian public schools. The survey had a predetermined target: students in the 7th or 8th grade of elementary school, or in the 3rd or 4th grade of high school. To conduct the survey, 501 schools from all over the country were randomly selected, with selection probability proportional to the number of student enrollments following three strata: geographical regions (North, Northeast, South, Southeast and Center-West), location area ( urban or rural), and course modality (regular or adult education). In each selected school, a class was randomly selected among the targeted ones. All students from the selected class were interviewed, as well as their Portuguese and Math teachers. Additionally, two parents and two staff members were interviewed. Unfortunately, it is not clear how these individuals were selected. All we know is that the parents should have their son or daughter enrolled in the selected class. Thus, they are not necessarily the mother and the father of a given student. Finally, the school's Principal was also interviewed. The sample contains 18,599 observations distributed in 353 municipalities.

The ADAE questionnaire has, among others questions, 18 statements (listed in the appendix) related to preference for racial discrimination. They either compare whites and blacks directly, or describe some aspect about blacks. Individuals are asked to choose one of four levels of agreement regarding the proposed statements: strongly disagree, somewhat disagree, somewhat agree or strongly agree. For example, the respondent is asked to choose the alternative that best indicates his level of agreement regarding the statement "In general, whites study harder than blacks".

As will become clear below, we use ADAE sample to construct the distribution of prejudice for each locality. Due to the reduced number of observations in a large number of municipalities from the sample (68\% with less than 40 observations), a local market is defined here as a set of geographically nearby integrated municipalities, denominated microregion by IBGE. In total, the 353 municipalities are distributed into 230 microregions. This will be the main unit of analysis of the paper.

The second main data source is the microdata from the 2010 Demographic Census, conducted by IBGE. This survey allows us to estimate wage differentials between whites and blacks for each local labor market. The Census sample consists of men between 25 and 60 years of age who live in one of the 230 microregions from the ADAE sample, whose occupation is not self-employed or employer, who work at least 30 hours per week and receive positive wage.

We use other data sources to construct control variables in order to isolate local microregional effects potentially associated with the variables of interest, the prejudice measures described below. Thus, we use information from 
2008 School Census (to assess the number of public schools) and 2007 Ideb (a Quality of School Index, elaborated by INEP). Also, we use local development indicators: the 2000 Municipal Human Development Index IDH-M jointly elaborated by the United Nations Development Programme (UNDP) in Brazil, the Institute for Applied Economic Research (IPEA), and João Pinheiro Foundation; and a health development index, elaborated by FIRJAN ${ }^{6}$ using public data. Finally, the 2010 Census is used in the construction of the Gini index (measuring household income inequality). All databases used in this paper are public and available for download.

\subsection{Samples characteristics}

In this paper, it is assumed that the ADAE sample is an employers' representative sample. Table 1 shows the ADAE sample characteristics. Most of the respondents live in urban areas, women are overrepresented, and, because $81 \%$ of the respondents are students, the mean age is around 24 . The average years of schooling (7.3) is higher than the average schooling for the entire population in Brazil (5, according to PNAD 2008). In this table, we separate blacks from browns. Thus, $4.3 \%$ of the respondents self-reported themselves as blacks, while almost $60 \%$ declared to be brown (pardo), moreno, mulatto or native ${ }^{7}$. Considering brown as part of the minority, the proportion of blacks in the sample, $63 \%$, is higher than the mean in the Brazilian population (around 53\%).

Table 1: Characteristics of ADAE sample

\begin{tabular}{|c|c|c|}
\hline & mean & s.d. \\
\hline Urban & 0.957 & 0.203 \\
\hline Woman & 0.597 & 0.490 \\
\hline Age & 23.7 & 12.4 \\
\hline Years of scholing & 7.3 & 2.6 \\
\hline White & 0.369 & 0.483 \\
\hline Black & 0.043 & 0.202 \\
\hline Brown & 0.588 & 0.492 \\
\hline Type of interviewee & & \\
\hline Students ${ }^{*}$ & 0.811 & 0.391 \\
\hline Students at school age ${ }^{* *}$ & 0.552 & 0.497 \\
\hline Observations & & 18599 \\
\hline \multicolumn{3}{|c|}{$\begin{array}{l}\text { Source: Discriminatory Actions in the School } \\
\text { (ADAE) survey, 2008. White includes Asians. } \\
\text { Brown includes all races but whites and blacks. } \\
\text { Students include regular-elementary, regular-high } \\
\text { school, adult-elementary and adult-high school. } \\
\text { Non-students include parents, School Principal, } \\
\text { teachers and staff members. }{ }^{*} \text { Students enrolled } \\
\text { in regular-elementary and regular-high school } \\
\text { courses. }\end{array}$} \\
\hline
\end{tabular}

\footnotetext{
${ }^{6}$ Federation of Industries of State of Rio de Janeiro.

${ }^{7}$ Native includes indigenous people as well as white-native (caboclo) and black-native (cafuso) descendants. They represent $2 \%$ of the sample.
} 
In Brazil, employers are mainly men (73\%) and have the highest average levels of education among all positions in occupation ( 9.7 years of schooling, PNAD 2008). Therefore, there is a concern related to the representativeness of the ADAE sample. As mentioned before, the sample comes from public schools, which means there could be little correspondence between the sample and the employer population in several socioeconomic aspects. Nevertheless, it is not necessary that the sample be strictly representative of employers. At first, all we need is that individuals in the ADAE sample exhibit similar discriminatory behavior one would expect employers to have. If prejudice and discriminatory behavior are disseminated in the society, this will probably be the case. Unfortunately, there is no way to test this assumption. However, one can assert that if the marginal discriminator's index of prejudice (see below) provided by ADAE sample is higher than the true parameter in all microregions (which basically means that the sample would produce a more prejudiced marginal employer than the population), then we will probably have a higher correlation between the index of prejudice and the racial wage gap than one would expect with a representative sample. We are going to argue that this is not the case, and that it would be very difficult to rationalize our results if the representativeness assumption is violated.

\subsection{Index of Discrimination}

As discussed in Section 3, in order to test Becker's model, it is necessary to recover some moments of the distribution of employer's prejudice. The first step in this direction is obtaining an individual index of prejudice. From this index, we can construct the distribution of prejudice for each microregion, and hence, assess any of its moments.

The individual Index of Discrimination, $I D_{i}$, based on Charles \& Guryan (2008), is generated from the respondents evaluation about the ADAE statements mentioned above. To transform qualitative variables into quantitative ones, we adopt the simplest possible way: for each question, values 1 to 4 are assigned to each response, with 1 being "strongly disagree" and 4, "strongly agree". Performing this way, higher values are associated with more discrimination. The $I D_{i}$ is equal to the average of the normalized variables, i.e.

$$
I D_{i}=\frac{1}{Q_{i}} \sum_{q=1}^{Q_{i}} \frac{X_{i q}-\bar{X}_{q}}{s d\left(X_{q}\right)}
$$

where $Q_{i}$ is the number of statements evaluated by the respondent $i, X_{i q}$ is the observed response of individual $i$ to the statement $q$, and $\bar{X}_{q}$ and $s d\left(X_{q}\right)$ are the average of $X_{i q}$ and its standard deviation for the statement $q$ across $i$. The index values do not have a meaningful quantitative interpretation; only indicate that the higher the value, the more prejudiced is the individual. Ranking this index across individuals within each micro-region recovers the distribution of prejudice for each micro-region.

Figure 1 shows the regional differences of racial prejudice and the composition of the population. It is one can see the cumulative distribution of the discrimination index. It is observed that the North appears more prone to discrimination against blacks, followed by the Northeast. The Southeast, in its turn, is the geographical region less prone to discrimination. On the right side of the figure, the proportion of blacks by macro-region is presented. 
Generally speaking, prejudice and proportion of blacks seem to be positively correlated.

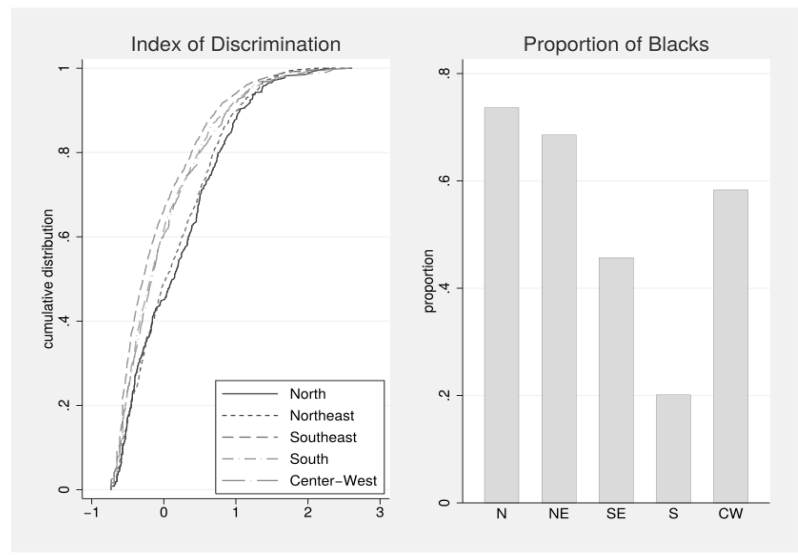

Figure 1: Cumulative distribution of the Index of Discrimination and Distribution of the proportion of blacks by macro-region

Table 2 investigates the relationship between personal attributes and prejudice at the individual level using the ADAE sample. In addition to the controls shown in the table, all regressions include dummies for states and groups of interviewees ${ }^{8}$. Column (1) presents a regression of the index of discrimination on individual characteristics. Women and more educated people discriminate less. Although our sample is composed of less educated people than employers are, they are more educated than average, and will be even more educated when the students, who represent $81 \%$ of the sample, finish school. In addition, it is possible that we have a less prejudiced sample because women are overrepresented (remember that a large share of employers is male). Thus, if the representativeness assumption were violated, our measures of prejudice would probably capture less prejudice than we truly have among employers.

In Table 2, we separate blacks from browns again. Whites discriminate more against blacks than blacks and browns. On the other hand, column (1) shows that even among non-whites there is some room for discriminatory behavior, since browns discriminate more than blacks. This distinct behavior among non-whites is documented by Kreisman \& Rangel (2015) in a different context for the US, where darker black NLSY1997 survey interviewers tend to classify blacks as lighter blacks than whites. Because the share of whites in the ADAE sample is less than this share among employers, and because whites discriminate more against blacks, again, we might be pushing the degree of prejudice of the potential marginal discriminator toward zero with this sample.

The same association between the index of prejudice and individual characteristic can be seen in the remaining columns of Table 2. Each of them

\footnotetext{
${ }^{8}$ Parents, principals, teachers, staff members and courses.
} 
shows the regression coefficients for the dependent variable resulting from a specific statement. In column (5), for example, the statement is "Blacks have gotten more than they deserve". According to the results, women agree less with this statement than men. The same goes for "Whites are more evolved" in column (3).

Comparing to the results reported by Charles \& Guryan (2008) for the US, more educated people also discriminate less in that country. On the other hand, there is a difference in relation to the behavior of men and women. Depending on the statement, men can discriminate less in the US. While it is clear that these country differences may result from distinct questions and sample composition of the surveys, the fact is that just as in the United States, where racial segregation officially existed until a few decades ago, in Brazil, where some people claim there exist a Racial Democracy, there is a clear pattern in preferences for discrimination as well. We are going to argue that this pattern reaches the labor market, influencing the outcomes.

Table 2: Discrimination and Individual Characteristics - ADAE sample

\begin{tabular}{|c|c|c|c|c|c|c|}
\hline & $\begin{array}{l}\text { Index of } \\
\text { Discrimi- } \\
\text { nation }\end{array}$ & $\begin{array}{l}\text { Whites } \\
\text { enjoy study } \\
\text { more than } \\
\text { Blacks do }\end{array}$ & $\begin{array}{c}\text { Whites } \\
\text { are more } \\
\text { evolved than } \\
\text { Blacks }\end{array}$ & $\begin{array}{l}\text { Whites } \\
\text { are } \\
\text { superior } \\
\text { to Blacks }\end{array}$ & $\begin{array}{c}\text { Blacks } \\
\text { have gotten } \\
\text { more than } \\
\text { they deserve }\end{array}$ & $\begin{array}{c}\text { Blacks } \\
\text { should try } \\
\text { to be like } \\
\text { Whites }\end{array}$ \\
\hline & (1) & (2) & (3) & (4) & (5) & (6) \\
\hline Brown & $\begin{array}{c}-0.030^{* * *} \\
(0.011)\end{array}$ & $\begin{array}{c}-0.076^{* * *} \\
(0.021)\end{array}$ & $\begin{array}{c}-0.054^{* * *} \\
(0.020)\end{array}$ & $\begin{array}{c}-0.002 \\
(0.020)\end{array}$ & $\begin{array}{l}-0.004 \\
(0.019)\end{array}$ & $\begin{array}{c}-0.042^{* *} \\
(0.020)\end{array}$ \\
\hline Black & $\begin{array}{c}-0.132^{* * *} \\
(0.027)\end{array}$ & $\begin{array}{c}-0.227^{* * * *} \\
(0.043)\end{array}$ & $\begin{array}{c}-0.184^{* * * *} \\
(0.044)\end{array}$ & $\begin{array}{c}-0.088^{*} \\
(0.049)\end{array}$ & $\begin{array}{c}-0.106^{* * *} \\
(0.047)\end{array}$ & $\begin{array}{c}-0.183^{* * * *} \\
(0.047)\end{array}$ \\
\hline Woman & $\begin{array}{c}-0.176^{* * *} \\
(0.011)\end{array}$ & $\begin{array}{c}-0.223^{* * *} \\
(0.019)\end{array}$ & $\begin{array}{c}-0.186^{* * * *} \\
(0.019)\end{array}$ & $\begin{array}{c}-0.154^{* * *} \\
(0.019)\end{array}$ & $\begin{array}{c}-0.178^{* * *} \\
(0.019)\end{array}$ & $\begin{array}{c}-0.206^{* * * *} \\
(0.019)\end{array}$ \\
\hline Age & $\begin{array}{l}-0.000 \\
(0.001)\end{array}$ & $\begin{array}{l}-0.000 \\
(0.001)\end{array}$ & $\begin{array}{l}0.002^{*} \\
(0.001)\end{array}$ & $\begin{array}{c}-0.002^{*} \\
(0.001)\end{array}$ & $\begin{array}{c}-0.003^{* *} \\
(0.001)\end{array}$ & $\begin{array}{c}0.005^{* * *} \\
(0.001)\end{array}$ \\
\hline Schooling & $\begin{array}{c}-0.030^{* * *} \\
(0.004)\end{array}$ & $\begin{array}{c}-0.031^{* * *} \\
(0.007)\end{array}$ & $\begin{array}{c}-0.033^{* * * *} \\
(0.007)\end{array}$ & $\begin{array}{c}-0.028^{* * *} \\
(0.006)\end{array}$ & $\begin{array}{c}-0.034^{* * *} \\
(0.007)\end{array}$ & $\begin{array}{c}-0.037^{* * * *} \\
(0.007)\end{array}$ \\
\hline Urban & $\begin{array}{c}-0.066^{* *} \\
(0.029)\end{array}$ & $\begin{array}{l}-0.081 \\
(0.054)\end{array}$ & $\begin{array}{l}-0.007 \\
(0.054)\end{array}$ & $\begin{array}{l}-0.091 \\
(0.058)\end{array}$ & $\begin{array}{c}-0.086^{*} \\
(0.052)\end{array}$ & $\begin{array}{c}-0.092^{*} \\
(0.052)\end{array}$ \\
\hline Obs. & 18,114 & 18,054 & 18,059 & 17,98 & 18,023 & 18,027 \\
\hline R-squared & 0.109 & 0.040 & 0.046 & 0.059 & 0.051 & 0.048 \\
\hline
\end{tabular}

\subsection{The marginal discriminator}

According to Becker's model, it is not the average discriminator that determines the wage gap, but rather the marginal one. In order to test the model it is necessary to obtain the discrimination coefficient of the marginal employer for each micro-region. Following Charles \& Guryan (2008), we define the marginal discriminator as the one who is located at the percentile of the distribution of the discrimination index equal to the proportion of blacks in the respective micro-region. This idea comes from the theoretical model. According to the model, under other specific conditions, if all employers hire the same number of employees and the sorting mechanism is at work, the proportion of employers who hire blacks would be equal to the proportion of blacks. In other words, if in the city of São Paulo it is estimated that $15 \%$ of the population is black, then the coefficient associated with the individual located at the 15th percentile of the distribution of the discrimination index for 
São Paulo is considered the coefficient of the marginal discriminator. Strictly speaking, for this procedure to identify the marginal employer it would be required that employers were a random sample of the general population in terms of discrimination and each hired the same number of workers.

Besides the marginal employer index, the average and other moments of the distribution are also needed not only for control purposes but also to assess robustness of the results and test alternative hypotheses. Specifically, variables that indicate the coefficients of discrimination for individuals located at the 10th, 50th and 90th percentiles of the distribution of prejudice for each micro-region are used, following Charles and Guryan's strategy.

\subsection{Descriptive analysis}

Table 3 presents descriptive statistics at the microregion level for the main variables used in the paper. It is observed that the conditional wage gap between whites and blacks is -0.091 log points, i.e., blacks earn about $91 \%$ of whites' mean wage on average. This number comes from the first stage of the empirical strategy described in the next section, and was estimated using 2010 Census microdata.

Table 3: Descriptive statistics at the micro-region level

\begin{tabular}{lcc}
\hline & mean & s.d. \\
\hline Conditional wage gap & -0.091 & 0.105 \\
\hline Black & 0.543 & 0.214 \\
Average Prejudice & 0.013 & 0.196 \\
Marginal Prejudice & -0.006 & 0.452 \\
10th percentile & -0.580 & 0.083 \\
50th percentile & -0.107 & 0.249 \\
90th percentile & 0.775 & 0.324 \\
\hline Public schools per 10,000 inhab. & 14.9 & 13.4 \\
Ideb 2007 & 3.518 & 0.611 \\
IFDM-Health & 0.768 & 0.102 \\
IDH-M & 0.733 & 0.082 \\
Gini household income & 0.543 & 0.061 \\
\hline ADAE-Obs. per microregion & 80.7 & 112.3 \\
Observations & 230 & \\
\hline
\end{tabular}

Note: Conditional wage gap estimated in the first stage using

2010 Census microdata sample composed of men 25-60 years-old, who are neither employer nor self-employed, worked at least 30 hours per week and received positive wage.

The variable Black indicates the percentage of blacks in each microregion. As one can see, more than half of our sample is black, since we are considering browns as minority. The variable Average Prejudice indicates the average of $I D_{i}$ (coefficient of discrimination) across individuals in each microregion. The variable Marginal Prejudice refers to the discrimination coefficient associated with the marginal employer. The number in the table is the mean index of the 
individuals located at the percentile associated with the proportion of blacks in the microregion. On average, the marginal employer is located at the 54th percentile of the prejudice distribution. Because Marginal Prejudice is less than Average Prejudice, the set of "marginal employers" is less prejudiced than the population, which is consistent with what one would expect from an employer's representative sample.

The next three variables contain the discrimination coefficient for each indicated percentile. Thus, both the average level of discrimination and the discrimination of the marginal employer are below the median of the distribution of prejudice.

In Table 3 we also have the variables used to control for possible confounding factors, which will be explained below. The (log of) number of public schools per ten thousand inhabitants is used to control for access to education. To control for quality of education, we use the $2007 \mathrm{Ideb}^{9}$. It combines student performance and flow rates for 5th and 9th grades of Elementary School and 3rd grade of High School, and higher values indicate better quality. To control for quality of health, we have the IFDM-Health index ${ }^{10}$, which combines information related to prenatal consultancy, deaths by undefined causes, and children deaths by avoidable causes. Again, higher values mean better quality of health. Finally, in addition to a measure for local inequality (the Gini index for per capita household income), we have a proxy for local development: the municipal Human Development Index (IDH-M $)^{11}$.

Table 3 also shows that the ADAE's average number of observations used to calculate the discrimination index by microregion is approximately 81 . Thus, for some microregions, there may be some difficulties in finding a percentile that matches the exact percentage of blacks in the population.

\section{Empirical strategy}

The empirical exercise is to analyze the relationship between the racial wage gap on the one side, and the proportion of blacks and measures of prejudice on the other. Following Charles \& Guryan (2008), we adopt a procedure in two stages by OLS. Because discrimination measures are defined at the microregion level, we first estimate the conditional wage gap for each location, using a regression at the individual level. Then, the estimated wage gaps become the dependent variable in the second stage, estimated at the microregional level. This second regression is actually a WLS, as we weight observations by the precision of the first stage estimates of the dependent variable, i.e, by the inverse of the standard errors. Each microregion, which is a set of integrated municipalities geographically near each other, is interpreted as a local market with relatively homogeneous socioeconomic and productive characteristics.

To estimate the wage differential in each micro-region, we use the Mincerian equation below:

\footnotetext{
${ }^{9}$ Índice de Desenvolvimento da Educação Básica (Index of Development of Basic Education).

${ }^{10}$ The FIRJAN Index of Development of Health.

${ }^{11}$ This is the Brazilian municipal version of the well-known Human Development Index. To obtain an index to the micro-regions, we compute the average IDH-M for the municipalities in each micro-region weighted by the population size. The same procedure was applied to the FIRJAN Health Index.
} 


$$
\ln \left(\text { wage }_{i}=\alpha+\sum_{j} \delta_{j} \text { race }_{i} \times \text { microregion }_{j}+\gamma^{\prime} X_{i}+\epsilon_{i}\right.
$$

where wage is the hourly wage of individual $i$, race is a dummy for blacks, microregion $_{j}$ is a dummy for the micro-region $j, X$ is a vector of control variables including dummies for age ranges, schooling and micro-regions, and $\epsilon_{i}$ is the error term. Note that the dummy for blacks is always interacted with the dummies for micro-regions. Then $\delta_{j}$ refers to the black-white wage gap in the micro-region $j$.

Once we have the estimated vector $\widehat{\delta}$, it becomes the dependent variable in the second stage according to the following equation estimated at the microregion level:

$$
\widehat{\delta}_{j}=\mu+\beta^{\prime} Z_{j}+\lambda^{\prime} W_{j}+v_{j}
$$

where $Z$ is a vector whose elements vary according to the exercise performed, and may include the average discrimination index, the proportion of blacks, the index for the marginal discriminator, and the percentiles of the prejudice distribution. Because $\widehat{\delta_{j}}$ is composed of coefficients of dummies indicating blacks, their values are generally negative: the closer to zero, the smaller the estimated black-white wage gap. Therefore, it is expected that the main variables of interest included in $Z$, namely the proportion of blacks and the variable Marginal Prejudice, are inversely related to $\widehat{\delta_{j}}$. An increase in the proportion of blacks, for example, is expected be associated with a higher wage differential between blacks and whites, which implies a negative coefficient.

In addition to dummies for geographical regions (North, South, Southeast, Northeast, Center-West), the vector $W$ includes controls to capture unobservable direct effects of public goods provision on the wage gap, which could be confounded with the impact of variables in the vector $Z$. Specifically, there is a concern about a possible association between micro-region level unobservable characteristics and quality of labor and education. In principle, a negative coefficient for the variable Marginal may indicate that blacks have worse access to better-quality education and that the local labor market recognizes this fact, although not observable by the econometrician. The prejudice measured at the local level could capture in part this effect, but controlling for local public goods provision would minimize this problem. This is because blacks relative to whites are typically more affected and dependent on public goods such as public schools and hospitals. Thus, the presence of public goods could and should mitigate the wage gap by reducing the differences in productive attributes between races. As mentioned before, proxies for the presence of public goods refer to the number of public schools and the quality of school and health. We also control for micro-regions development through IDH-M, and for inequality through Gini index for household income. The latter, although potentially endogenous in the second stage, should also partially capture differences in access to public goods and will assist us in the discussion of results. 


\section{Results}

All the results discussed in this section refer to the second stage (equation 7) of the empirical strategy. In general, the Mincerian equation results of the first stage are in line with the literature ${ }^{12}$. In Table 4 , the dependent variable is the conditional wage gap between blacks and whites estimated in the first stage. Each column represents a WLS regression at the microregional level, where observations are weighted by the precision of the first stage estimates of the dependent variable.

The first three columns present the correlation between our main variables of interest and the racial wage gap. Intuitively, one would expect a positive relationship between the average discrimination and the wage differential, i.e. that the higher the average prejudice at the microregion, the larger the wage gap between blacks and whites. Column (1) shows that this is the case (remember that the closer the dependent variable is to zero, the lower the wage gap), but the estimated coefficient is not statistically significant. On the other hand, as expected by Becker's model, column (2) shows that the higher the prejudice of the marginal employer, the larger the wage gap tends to be.

Table 4: Wage gap and racial discrimination

\begin{tabular}{lcccccc}
\hline & $(1)$ & $(2)$ & $(3)$ & $(4)$ & $(5)$ & $(6)$ \\
\hline Average & -0.049 & & & 0.004 & -0.033 & -0.014 \\
Marginal & $(0.034)$ & & & $(0.032)$ & $(0.031)$ & $(0.048)$ \\
& & $-0.033^{* *}$ & & $-0.034^{* *}$ & & -0.016 \\
\% Black & & $(0.016)$ & & $(0.017)$ & & $(0.044)$ \\
& & & $-0.063^{* *}$ & & $-0.056^{* *}$ & -0.031 \\
Observations & 230 & 230 & 230 & 230 & 230 & 230 \\
R-squared & 0.012 & 0.033 & 0.028 & 0.033 & 0.033 & 0.034 \\
\hline
\end{tabular}

Note: Robust standard errors in parenthesis; ${ }^{* *} \mathrm{p}<0.01,{ }^{* *} \mathrm{p}<0.05,{ }^{*} \mathrm{p}<0.10$. First stage sample includes men 25-60 years-old, who are neither self-employed nor employer, with positive wages. Regressions weighted by the precision of the first stage estimates of the dependent variable (inverse of the standard error).

Column (4) includes the average of the index of discrimination and the prejudice of the marginal employer in the same regression. Exactly as predicted by the model, the most significant event for the formation of the wage gap is the degree of prejudice of the marginal employer and not the average prejudice among employers. The Average is still not significant when both variables enter the equation. Actually, even its sign is not the one expected at a first glance. To get a quantitative idea about the importance of preference discrimination on the determination of the wage gap, according to column (4), an increase of one standard deviation in the variable Marginal increases the wage gap in 1.53 percentage points. Considering the conditional wage gap of $9.1 \%$ (Table 3 ), this impact represents a positive increase of $17 \%$.

Another prediction of the model is related to the role of the proportion of blacks in the labor market. Column (3) indicates that localities with higher proportion of blacks are those that have higher wage differentials, as predicted by the model. Column (5) indicates that this relationship remains the same

${ }^{12}$ These results are available upon request. 
after the inclusion of the average discrimination in the regression. Quantitatively, an increase of 21.4 percentage points in the proportion of blacks (one standard deviation) leads to an increase of $13 \%$ of the conditional wage gap. This result is somewhat counterintuitive, since one could argue that the larger the relative size of the minority, the higher will be the contact between groups, increasing the probability of reducing discrimination through social interaction. This is an anecdotal reasoning typically repeated in Brazil due to its mixed society, but that is not present in the data: places with a higher proportion of blacks have a higher wage gap between whites and blacks in the labor market. In addition, this finding adds to what was discussed before, i.e., that there is a positive correlation between discrimination and proportion of blacks. It is worth to remember that these results control for return to education through the first stage. It could be the case that the wage gap is higher not due to the mechanism described by Becker, but because the return to education is higher for whites where there is a higher proportion of blacks, since blacks are less educated on average. Our results show that this is not the case.

In this paper, we prefer not to include the percentage of blacks and the variable Marginal together in the regression analysis. The reasoning for this is that, by construction, the variable Marginal is a function of the percentage of blacks. As discussed in section 4.4, the value of the index of discrimination of the marginal employer is the result of a match between the percentage of blacks and the associated percentile of the distribution. Thus, in the regression, it does not make much sense to vary the percentage of blacks while keeping the variable Marginal constant, because this necessarily changes the identity of the marginal discriminator. In any case, the inclusion of these three variables in the same regression (column 6) results in the same negative effects for the percentage of blacks and the variable Marginal, although none of them are significant, an expected result due to multicollinearity. Also, the point estimate of the variable Average is still close to zero.

In summary, the effects discussed so far present a remarkable result that would be very difficult to rationalize outside the environment of Becker's model. In Brazil's context, this is even more surprising since one does not clearly observe the same level of racial tension in its society as one can observe in the United States, for example. In the following sections, we argue that, in spite of that, those are very robust results.

\subsection{Public Goods}

Table 5 presents the estimates including controls for public services. The table refers to the specification where we include the variable Marginal Prejudice. We discuss the results including the proportion of blacks later on. Column (1) repeats columns (4) of Table 4 . The other columns add previously discussed controls in an attempt to minimize the possibility that the locally measured index of discrimination capture effects of unobservable productivity characteristics that determine the wage gap, such as the quality of education.

As one can see, in general, the effect of the variable Marginal maintains the expected sign and is statistically significant at $5 \%$ in all but one specification after including controls. In particular, column (3) to (5) present the same coefficient in spite of distinct control vectors. In a broader perspective, this scenario suggests that our measure of prejudice is quite orthogonal to other factors potentially associated with the wage gap. 
Table 5: Incorporating public goods and other controls

\begin{tabular}{lcccccc}
\hline & $(1)$ & $(2)$ & $(3)$ & $(4)$ & $(5)$ & $(6)$ \\
\hline Marginal & $-0.034^{* *}$ & $-0.054^{* *}$ & $-0.054^{* *}$ & $-0.052^{* *}$ & $-0.055^{* *}$ & $-0.045^{*}$ \\
& $(0.017)$ & $(0.027)$ & $(0.023)$ & $(0.025)$ & $(0.024)$ & $(0.023)$ \\
Average & 0.004 & 0.019 & -0.022 & -0.022 & -0.024 & -0.021 \\
& $(0.032)$ & $(0.036)$ & $(0.036)$ & $(0.037)$ & $(0.037)$ & $(0.036)$ \\
Public Schools & & & $0.028^{* *}$ & $0.028^{* *}$ & $0.034^{* * *}$ & 0.014 \\
& & & $(0.012)$ & $(0.012)$ & $(0.012)$ & $(0.011)$ \\
Ideb 2007 & & $0.037^{* * *}$ & $0.037^{* * *}$ & $0.023^{* *}$ & 0.007 \\
IFDM Health & & & $(0.008)$ & $(0.009)$ & $(0.012)$ & $(0.010)$ \\
IDH-M & & & 0.013 & 0.052 & 0.033 \\
Gini & & & $(0.087)$ & $(0.086)$ & $(0.082)$ \\
& & & & & $-0.280^{*}$ & -0.131 \\
\hline Region dummies & & & & & $(0.161)$ & $(0.151)$ \\
Observations & 230 & 230 & 230 & 230 & & $-0.525^{* * *}$ \\
R-squared & 0.033 & 0.042 & 0.184 & 0.184 & 0.194 & $0.103)$ \\
\hline Robust standar & & & & & $\mathrm{X}$ & 0.293 \\
\hline
\end{tabular}

Robust standard errors in parenthesis. ${ }^{* * *} \mathrm{p}<0.01,{ }^{* *} \mathrm{p}<0.05,{ }^{*} \mathrm{p}<0.10$. First stage sample includes men 25-60 years-old, who are neither self-employed nor employer, with positive wages.

Regressions weighted by the precision of the first stage estimates of the dependent variable

(inverse of the standard errors). 
Column (2) includes dummies to account for geographical regions effects (North, Northeast, Southeast, South and Center-West) and shows that there are no such issues. The biggest concern of our empirical strategy would be the possibility of unobserved factors related to quality of education being correlated with our measure of prejudice. Column (3) includes the number of public schools per 10 thousands inhabitants and the Ideb, a quality of education index. As expected, both variables are associated with less discrimination in the labor market. A larger number of schools reaches a larger share of blacks who, as a minority, are those who need them most and most benefit from them, making localities better provided with public schools to have lower wage gaps. In addition, it is certainly not enough to have access to education. The Ideb index controls for the quality of education the minority has access to. Better-quality schools mean that possible differences in unobserved productivity characteristics are minimized, which implies that the black-white wage gap should be lower. Both variables are significant in all specifications, except when we include the Gini index for household per capita income. We are going to discuss Gini index later in this section. Nevertheless, the point here is that there is no change in the estimated coefficient of the marginal discriminator after the inclusion of these controls.

Another threat to our empirical strategy is the unobservable aspects related to health. Better access to health would be associated with a more productive minority, which would decrease the observed wage gap and could be correlated with the measure of prejudice. However, column (4) shows that this seems to not be the case: the IFDM index of health controls for quality of health in each microregion and, in spite of being negatively correlated to the wage gap, it is not statistically significant and its inclusion does not change the variable Marginal.

Column (5) includes a measure of local development, the local Human Development Index (IDH-M). There is this idea that more developed societies are less prejudiced. If this is true, our variables of interest may be capturing local development instead of prejudice. By comparing the coefficients of the variable Marginal in column (6) to the other columns, one can see that there is no such relationship since, again, there is no change in the coefficient of the marginal discriminator. This is our preferred specification. An increase of one standard deviation in the variable Marginal increases the racial wage gap by $27 \%$.

It is interesting, though, that the IDH-M coefficient turns out to be negative, suggesting a positive correlation to the racial wage gap. Column (6) is useful to rationalize this result. It includes the Gini index of household income in the regression, along with the other controls. As expected, inequality is associated with higher wage gaps. This correlation ascends because the Gini index is potentially endogenous, since it contributes to the wage gap. But inequality can also be interpreted as a broader measure of access to education and health. After including the Gini index in the regression, the effect of education variables vanishes, a result that can be attributed to the correlation between inequality and public services. This also happens to the IDH-M: it suggests that inequality and local development are positively correlated in Brazilian microregions, since the IDHM coefficient decreases in absolute terms. The more relevant result, though, is that controlling for inequality causes no substantial change in the effect of the variable of interest: the Marginal remains negative and significant at $10 \%$. 


\subsection{Nonlinearity of the percentage of blacks}

The results including the percentage of blacks instead of the variable Marginal are quite similar qualitatively. Because of that, it is more interesting to discuss the possibility of nonlinear effects of the percentage of blacks. Table 6 reports specifications testing this nonlinearity hypothesis. Column (1) includes the linear variable only, while column (2) includes a quadratic term, and column (3) substitutes dummies representing quartiles of the percentage of blacks' distribution with the continuous variables. All specifications include the same controls as column (5) of Table 5.

Table 6: Nonlinear effects of percentage of blacks

\begin{tabular}{|c|c|c|c|}
\hline & (1) & $(2)$ & (3) \\
\hline$\%$ Black & $\begin{array}{c}-0.126^{* *} \\
(0.049)\end{array}$ & $\begin{array}{c}0.171 \\
(0.151)\end{array}$ & \\
\hline (\% Black) squared & & $\begin{array}{c}-0.296^{* *} \\
(0.144)\end{array}$ & \\
\hline$\%$ Black - 2nd quartile dummy & & & $\begin{array}{c}-0.013 \\
(0.016)\end{array}$ \\
\hline$\%$ Black - 3rd quartile dummy & & & $\begin{array}{c}-0.035^{*} \\
(0.019)\end{array}$ \\
\hline$\%$ Black - 4th quartile dummy & & & $\begin{array}{c}-0.060^{* *} \\
(0.023)\end{array}$ \\
\hline Observations & 230 & 230 & 230 \\
\hline R-squared & 0.200 & 0.212 & 0.202 \\
\hline \multicolumn{4}{|c|}{$\begin{array}{l}\text { Robust standard errors in parenthesis. }{ }^{* *} \mathrm{p}<0.01,{ }^{* *} \mathrm{p}<0.05,{ }^{*} \mathrm{p}<0.10 \text {. } \\
\text { Regressions include the same controls as column (5) of Table 5, except the } \\
\text { variable Marginal. First stage sample includes men } 25-60 \text { years-old, who are } \\
\text { neither self-employed nor employer, with positive wages. Regressions } \\
\text { weighted by the precision of the first stage estimates of the dependent } \\
\text { variable (inverse of the standard errors). }\end{array}$} \\
\hline
\end{tabular}

The linear specification suggests that each 10 percentage point increase in the percentage of blacks increases the racial wage gap by 1.26 percentage points, which represents $14 \%$ of the conditional wage gap. On the other hand, column (2) shows that when the percentage of blacks is low, there is actually a decrease (at a decreasing rate) in the racial wage gap, although the linear term is not significant. It also suggests that when the percentage of blacks reaches around $29 \%$, there is an inflection point in which the percentage of blacks starts to have a positive effect on the racial wage gap. It is worth noting that the average percentage of blacks across microregions is $54.3 \%$, with a standard deviation of 21.4 . In almost $72 \%$ of the microregions we have more than $29 \%$ of blacks.

The lack of significance of the linear term in column (2) motivates the specification reported in column (3). As one can see, the effect of the percentage of blacks is increasing through the quartiles of the distribution, and is statistically significant at $10 \%$ for the highest two. This means that the consequences of prejudice discrimination are more severe in locations where the minority is actually the largest group of the population. Remember the discussion in Section 2, where we highlighted that in Brazil, when one considers browns as part of the minority, the minority becomes the largest group in the country. Despite that, compared to locations where blacks are minority de facto, they are even more discriminated. 


\subsection{Moments of the Distribution}

Average discrimination can be interpreted as a control for the distribution of prejudice. In this sense, we showed that the index of discrimination of the marginal employer has a positive effect on the black-white wage gap, keeping that distribution fixed. In order to better control for the distribution of prejudice, we test alternative specifications by substituting the index of discrimination related to percentiles of the distribution of prejudice for the average discrimination ${ }^{13}$. Table 7 presents the estimated coefficients of equation (7) after the inclusion of three distribution percentiles in two distinct regressions: 10 th, 50th and 90th in column (1) and 20th, 50th and 80th in column (2). The idea is to discard the possibility that the variable Marginal is actually capturing the effect of some specific moment of the distribution instead of the effect of the marginal discriminator. Both specifications include the same controls as column (5) of Table 5.

The results of these alternative specifications are very similar to the previously discussed. The Marginal coefficients remain negative and statistically significant at $10 \%$. More importantly, none of the variables representing moments of the prejudice distribution presents a statistically significant coefficient. Because in Brazil the percentage of blacks varies considerably across microregions, we did not expect any specific percentile to be related to the wage gap ${ }^{14}$. We conclude that we are not capturing some unobservable effect of a particular point of the distribution.

\section{Final remarks}

This paper presents evidence of discrimination by preference in the Brazilian labor market. Specifically, using data from 2010 Census and Discriminatory Action in the School Survey (2008), two hypotheses derived from the model of employer discrimination (Becker, 1957) are tested, following a methodology similar to Charles \& Guryan (2008). The first hypothesis states that the wage gap is determined by the degree of prejudice of the marginal employer, and not by the average prejudice among employers. The second hyphothesis states that, given the distribution of prejudice, the higher the proportion of minority, the greater the wage gap will be.

Our estimates indicate that both hypotheses are true in the Brazilian case. In our preferred specification, an increase of one standard deviation in the degree of prejudice of the marginal employer results in an increase of $27 \%$ in the conditional wage differential between blacks and whites. Also, an increase of 10 percentage points in the proportion of blacks is associated with an increase of $14 \%$ in the wage gap. Despite the strong assumptions we have made to reach these numbers, it seems that the label Racial Democracy does not fit so well to Brazil's society.

In addition, these results have an important consequence for public policy. If, indeed, we are facing wage differentials caused by discrimination by prefer-

\footnotetext{
${ }^{13}$ The use of percentiles is inspired by Charles \& Guryan (2008) who use it in a different context.

${ }^{14}$ In the United States, the percentage of blacks is relatively constant across states $(10 \%)$. Thus, Charles \& Guryan (2008) consider the 10th percentile a proxy for the marginal discriminator. In their case, it is natural to expect a high correlation between the 10th percentile and the variable Marginal.
} 
Table 7: Including controls for the moments of distribution

\begin{tabular}{|c|c|c|}
\hline & (1) & (2) \\
\hline Marginal & $\begin{array}{r}-0.047^{*} \\
(0.025)\end{array}$ & $\begin{array}{c}-0.054^{* *} \\
(0.025)\end{array}$ \\
\hline 10th percentile & $\begin{array}{r}-0.045 \\
(0.094)\end{array}$ & \\
\hline 20th percentile & & $\begin{array}{c}0.044 \\
(0.089)\end{array}$ \\
\hline 50th percentile & $\begin{array}{c}-0.002 \\
(0.042)\end{array}$ & $\begin{array}{c}-0.053 \\
(0.058)\end{array}$ \\
\hline 80th percentile & & $\begin{array}{c}0.012 \\
(0.030)\end{array}$ \\
\hline 90th percentile & $\begin{array}{r}-0.022 \\
(0.020) \\
\end{array}$ & \\
\hline Observations & 230 & 230 \\
\hline R-squared & 0.199 & 0.197 \\
\hline \multicolumn{3}{|c|}{$\begin{array}{l}\text { Note: Robust standard errors in parenthesis. }{ }^{* * *} \\
\mathrm{p}<0.01,{ }^{* *} \mathrm{p}<0.05,{ }^{*} \mathrm{p}<0.10 \text {. Second stage controls } \\
\text { are the same as column (5) of Table } 7 \text {. First stage } \\
\text { sample includes men } 25-60 \text { years-old, who are } \\
\text { neither self-employed nor employer, with positive } \\
\text { wages. Regressions weighted by the precision of } \\
\text { the first stage estimates of the dependent variable } \\
\text { (inverse of the standard errors). }\end{array}$} \\
\hline
\end{tabular}

ences, affirmative action policies, such as quotas for minorities in universities, will not eliminate the problem. One possible solution to mitigate the wage gap is to increase competition in the product market. This would force employers who discriminate out of business, or change their preferences. In any case, the wage gap tends to decrease.

\section{Acknowledgments}

This paper benefited from comments by Claudio Ferraz, Gustavo Gonzaga, Naercio Menezes-Filho, Rodrigo R. Soares, Gabriel Ulyssea, Renato Seixas, workshop participants at PUC-Rio, and anonymous referees. All remaining errors are my own. 


\section{Appendix A ADAE questions related to racial discrimination}

1. In general, whites are more dedicated students than blacks.

2. White children learn faster than black children.

3. Blacks are more violent than whites.

4. Blacks' body shape is good for physical labor.

5. Black students frequently cause disorder in school.

6. Whites deserve more valued jobs than blacks.

7. Whites enjoy study more than blacks do.

8. Blacks show off more than whites in social events.

9. Black women have more aptitude to be maid than white women.

10. Whites are more evolved than blacks.

11. White students are better behaved than blacks ones.

12. Whites are superior to blacks.

13. Blacks have gotten more than they deserve.

14. Blacks should not complain, they are where they should be.

15. Blacks should try to be like whites.

16. Nowadays, blacks have more political influence then they deserve.

17. Blacks are better cooker than whites.

18. Blacks have more ability to perform manual labor.

\section{Bibliography}

Antman, F. \& Duncan, B. (2015), 'Incentives to identify: Racial identify in the age of affirmative action', Review of Economics and Statistics (97)(2).

Anwar, S., Bayer, P. \& Hjamarsson, R. (2012), 'The impact of jury race on criminal trials', The Quarterly Journal of Economics 127, 1017-1055.

Becker, G. (1957), The Economics of Discrimination, University of Chicago press.

Bertrand, M. (2011), New perspectives on gender, Vol. 4, Part B of Handbook of Labor Economics, Elsevier, pp. 1543 - 1590.

URL: $h t t p: / / w w w . s c i e n c e d i r e c t . c o m / s c i e n c e / a r t i c l e / p i i / S 0169721811024154$

Bertrand, M. \& Mullainathan, S. (2004), 'Are emily and greg ore employable than lakisha and jamal? a field experiment on labor market discrimination', The American Economic Review 94(4,Sep), 991-1013.

Card, D. \& Krueger, A. B. (1992), 'School quality and black-white relative earnings: a direct assessment', The Quarterly Journal of Economics 107(1), 151-200.

Carneiro, P., Heckman, J. J. \& Masterov, D. V. (2003), 'Labor market discrimination and racial differences in premarket factors', Journal of Law and Economics 48(1), 1-39.

Charles, K. \& Guryan, J. (2008), 'Prejudice and wages: an empirical assessment of becker's the economics of discrimination', Journal of Political Economy 116(5), 773-809. 
Table A.1: Socioeconomic characteristics by race - Census 2010 - OLS regressions on race dummies (White omitted)

\begin{tabular}{|c|c|c|c|c|}
\hline & (1) & (2) & (3) & (4) \\
\hline Dep. Var. & Black & Brown & Cons. & $\begin{array}{l}\text { R-sq. } \\
\text { Obs. }\end{array}$ \\
\hline Monthly wage R\$ & $\begin{array}{c}-748.9^{* * * *} \\
(4.1)\end{array}$ & $-717.4^{* * * *}$ & $\begin{array}{c}1,638.4^{* * *} \\
(1.5)\end{array}$ & $\begin{array}{c}0.013 \\
8,274,330\end{array}$ \\
\hline Monthly household per capita income $\mathrm{R} \$$ & $\begin{array}{c}-551.7^{* * *} \\
(2.3)\end{array}$ & $\begin{array}{c}-575.9^{* * *} \\
(1.2)\end{array}$ & $\begin{array}{c}1,066.9^{* * * *} \\
(0.8)\end{array}$ & $\begin{array}{c}0.012 \\
20,451,100\end{array}$ \\
\hline Weekly hours worked & $\begin{array}{c}-0.576^{* * *} \\
(0.019)\end{array}$ & $\begin{array}{c}-0.976^{* * * *} \\
(0.011)\end{array}$ & $\begin{array}{c}40.129^{* * * *} \\
(0.007)\end{array}$ & $\begin{array}{c}0.001 \\
9,114,681\end{array}$ \\
\hline Economically active & $\begin{array}{c}0.011^{* * *} \\
(0.000)\end{array}$ & $\begin{array}{c}-0.040^{* * * *} \\
(0.000)\end{array}$ & $\begin{array}{c}0.594^{* * * *} \\
(0.000)\end{array}$ & $\begin{array}{c}0.002 \\
17,336,292\end{array}$ \\
\hline Unemployed & $\begin{array}{c}0.030^{* * * *} \\
(0.000)\end{array}$ & $\begin{array}{c}0.029^{* * * *} \\
(0.000)\end{array}$ & $\begin{array}{c}0.062^{* * * *} \\
(0.000)\end{array}$ & $\begin{array}{c}0.003 \\
9,820,083\end{array}$ \\
\hline Household density (residents per room) & $\begin{array}{c}0.200^{* * * *} \\
(0.000)\end{array}$ & $\begin{array}{c}0.232^{* * * *} \\
(0.000)\end{array}$ & $\begin{array}{c}0.703^{* * * *} \\
(0.000)\end{array}$ & $\begin{array}{c}0.038 \\
20,412,854\end{array}$ \\
\hline Access to sanitary sewage general network & $-0.063^{* * * *}$ & $-0.160^{* * * *}$ & $\begin{array}{c}0.619^{* * * *} \\
(0.000)\end{array}$ & $\begin{array}{c}0.024 \\
19,563,130\end{array}$ \\
\hline Access to water supply general network & $\begin{array}{c}-0.036^{* * *} \\
(0.000)\end{array}$ & $\begin{array}{c}-0.084^{* * * *} \\
(0.000)\end{array}$ & $\begin{array}{c}0.854^{* * * *} \\
(0.000)\end{array}$ & $\begin{array}{c}0.011 \\
20,413,018\end{array}$ \\
\hline Garbage disposal - collected directly & $\begin{array}{c}-0.090^{* * *} \\
(0.000)\end{array}$ & $\begin{array}{c}-0.121^{* * *} \\
(0.000)\end{array}$ & $\begin{array}{c}0.848^{* * *} \\
(0.000)\end{array}$ & $\begin{array}{c}0.021 \\
20,413,018\end{array}$ \\
\hline Existence of computer with internet access & $\begin{array}{c}-0.067^{* * * *} \\
(0.001)\end{array}$ & $\begin{array}{c}-0.078^{* * * *} \\
(0.000)\end{array}$ & $\begin{array}{c}0.824^{* * * *} \\
(0.000)\end{array}$ & $\begin{array}{c}0.008 \\
6,709,611\end{array}$ \\
\hline Possession of car for personal use & $\begin{array}{c}-0.299^{* * *} \\
(0.000)\end{array}$ & $\begin{array}{c}-0.268^{* * *} \\
(0.000)\end{array}$ & $\begin{array}{c}0.540^{* * * *} \\
(0.000)\end{array}$ & $\begin{array}{c}0.078 \\
20,413,018\end{array}$ \\
\hline
\end{tabular}


Fryer, Jr., R. G. (2011), Racial inequality in the 21st century: The declining significance of discrimination, Vol. 4, Part B of Handbook of Labor Economics, Elsevier, pp. $855-971$.

URL: $h t t p: / / w w w . s c i e n c e d i r e c t . c o m / s c i e n c e / a r t i c l e / p i i / S 0169721811024087$

Goldin, C. \& Rouse, C. (2000), 'Orchestrating impartiality: The impact of 'blind' auditions on female musicians', American Economic Review 90(4), 715-741.

Hjort, J. (2014), 'Ethnic divisions and production in firms', The Quarterly Journal of Economics 129(4), 1899-1946.

Jaccoud, L. (2008), Racismo e república: O debate sobre o branqueamento e a discriminação racial no brasil, in $\mathrm{M}$. Theodoro, ed., 'As políticas públicas e a desigualdade racial no Brasil', pp. 45-64.

Kreisman, D. \& Rangel, M. A. (2015), 'On the blurring of the color line: Wages and employment for black males of different skin tones', Review of Economics and Statistics 97(1).

List, J. (2004), 'The nature and extent of discrimination in the marketplace: Evidence from the field', The Quarterly Journal of Economics 119(1), 49-89.

Neal, D. \& Johnson, W. (1996), 'The role of premarket factor in black-white differences', Journal of Political Economy 104(5), 869-895.

Nix, E. \& Qian, N. (2015), The fluidity of race: "passing” in the united states, 1880-1940, Working Paper 20828, National Bureau of Economic Research.

Osorio, R. G. (2003), O sistema classificatório de cor ou raça do ibge, Texto para Discussçao 996, IPEA.

Osorio, R. G. (2008), Desigualdade racial e mobilidade social no brasil: um balanço das teorias, in M. Theodoro, ed., 'As políticas públicas e a desigualdade racial no Brasil', pp. 65-95.

Phelps, E. S. (1972), 'The statistical theory of racism and sexism', The American Economic Review 62(4), 659-661.

Schwartzman, S. (1999), 'Fora de foco: diversidade e identidades étnicas no brasil', Novos Estudos CEBRAP 55, 83-96. 